\title{
FIELD STUDY ON THE DISTRIBUTION OF ENTAMOEBA HISTOLYTICA AND ENTAMOEBA DISPAR IN THE NORTHERN PHILIPPINES AS DETECTED BY THE POLYMERASE CHAIN REACTION
}

\author{
WINDELL L. RIVERA, HIROSHI TACHIBANA, AND HIROJI KANBARA \\ Department of Protozoology, Institute of Tropical Medicine, Nagasaki University, Nagasaki, Japan; Department of Infectious \\ Diseases, Tokai University School of Medicine, Isehara, Kanagawa, Japan
}

\begin{abstract}
We used the polymerase chain reaction (PCR) to study the distribution of Entamoeba histolytica and E. dispar in 1,872 individuals in 14 communities in the northern Philippines. Here we report a field study using a DNA extraction protocol from formalin-fixed stool specimens as previously reported. This assay detected 137 stools $(7.318 \%)$ containing $E$. dispar and 18 stools $(0.961 \%)$ containing $E$. histolytica. The most affected age group for $E$. histolyticalE. dispar infections were those 5-14 years of age. There was no significant difference in the sex distribution of $E$. histolytica, while in the case of E. dispar, a higher prevalence was observed in females $(9.186 \%)$ than in males $(5.731 \%)(P<0.01)$. An apparent clustering of stool-positive cases of $E$. histolytica and E. dispar was also observed in the northern part of the study area. The results of this survey demonstrate that $E$. dispar is highly prevalent in the communities studied. Moreover, it offers promise for the PCR using DNA extracted from formalin-fixed stools as a sensitive epidemiologic tool for detecting $E$. histolytica and E. dispar infections.
\end{abstract}

The intestinal protozoan parasite Entamoeba histolytica is the causative agent of human amebiasis. Entamoeba histolytica is responsible for up to 100,000 deaths per year, placing it second only to malaria in mortality due to protozoan parasites. ${ }^{1}$ The infection is common in developing countries and predominantly affects individuals with poor socioeconomic conditions, nonhygienic practices, and malnutrition.

A number of epidemiologic studies of E. histolytica infection were performed before the clear distinction of two separate species, E. dispar and E. histolytica, was established. ${ }^{2}$ Because they are morphologically indistinguishable, studies based on stool surveys have raised the question on the validity of most of these studies. Moreover, seroepidemiologic studies that were carried out in a number of endemic countries ${ }^{3-8}$ usually reflected the seroprevalence of the disease even in the near past. Also, the major problem with current serologic test results is that they remain positive for years after an episode of amebiasis. To date, the standardization of antigen preparation and the relative measurement of positive cut-off antibody titers for use in serodiagnosis still pose a problem.

In recent years, a number of methods such as isoenzyme typing, ${ }^{9}$ DNA probes for the polymerase chain reaction (PCR) and hybridization, ${ }^{10-13}$ restriction pattern analysis, ${ }^{14-19}$ and monoclonal antibodies ${ }^{20-24}$ have been developed for the clear distinction of the two species. Clearly, accurate diagnostic tools are required for the clinical and public health management of the disease. The use of a stool ELISA has recently been shown to be useful in routine diagnostic procedure and epidemiologic studies. ${ }^{25,26}$ However, a comparative study on the use of the ELISA and PCR for the detection of E. histolytica and E. dispar indicated that the PCR was more advantageous than the ELISA in epidemiologic studies. ${ }^{27}$ It is therefore important to assess the usefulness of the PCR in accumulating data on the prevalence of E. histolytica and $E$. dispar in the field that are more accurate.

We previously reported that a successful extraction of DNA from formalin-fixed stool samples for the PCR is a useful tool for rapid diagnosis of both E. histolytica and $E$. dispar infections. ${ }^{28}$ Here we report the application of this method to document the prevalence of the two species in a number of communities in the northern Philippines. Our preliminary hospital-based studies showed that amebic diarrheal diseases in Baguio City and nearby communities in the northern Philippines are frequent; however, their prevalence and distribution are not well-characterized. We therefore conducted a large-scale field study to determine the distribution of E. histolytica and E. dispar in these communities.

\section{MATERIALS AND METHODS}

Study sites. The study was conducted during the months of December 1995, January and December 1996, and January 1997 in the communities (locally called barangays) within and nearby Baguio City, The Philippines (Figure 1). This study area belongs to the Cordillera Autonomous Region and is the highest city in The Philippines, with an average altitude of 1,500 meters above sea level. Three major land forms characterize the relief features of the city: valley, plateau, and steep slopes. Throughout the year, the weather is cool but is coolest during the months of December to February with an average temperature of $18^{\circ} \mathrm{C}$.

Housing is inadequate in the city, given a rapid population increase and inadequate area for settlement expansion aside from poor economic conditions. Ninety-nine percent of the total number of households in the city have access to potable water. Only $0.95 \%$ of the total population have doubtful water sources, most of which are places where water pipes are inaccessible in view of the high elevation of the city.

Collection of samples. The day before the scheduled sample collection, the research team visited the randomly selected households, explained the purpose of the study and the requirements for sample collection, and distributed specimen cups. Particular care was taken in explaining the need to label the specimen cups with name, age, and sex and to avoid sample contact with soil and with samples from other individuals. Informed consent was obtained from all individuals. This protocol was approved by the Ethical Committees for Human Studies of the Institute of Tropical Medicine at Nagasaki University and Baguio General Hospital and Med- 


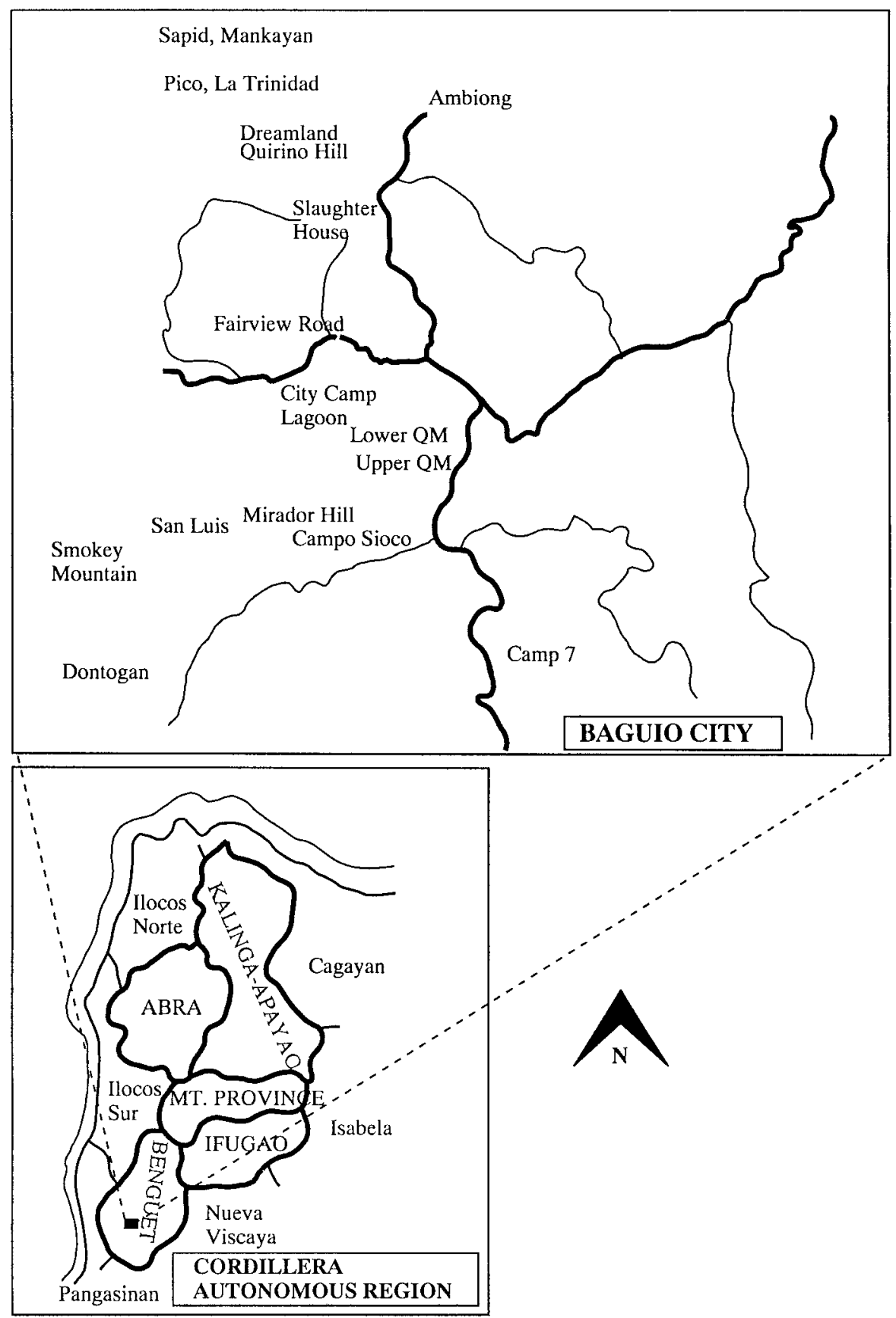

Figure 1. Map of Baguio City, The Philippines, showing the study areas.

ical Center (Baguio City, The Philippines). The samples were then collected the next morning and immediately transported to the laboratory. Each sample was macroscopically inspected for its consistency and for the presence of soil contamination, blood, or mucus. Routine microscopic diagnosis of parasites was then performed.

Microscopic examination of parasites. The presence of parasites was determined by microscopic examination of fresh stools and formalin-ether concentrated specimens.

Genomic DNA extraction and the PCR. Genomic DNA was extracted from cysts present in formalin-fixed stool specimens as previously described ${ }^{28}$ with slight modifications. Briefly, the pellet resulting from the sedimentation procedure was washed four times with phosphate-buffered saline. The pellet from the last wash was resuspended in TE buffer (100 mM Tris, pH 8.0, and 25mM EDTA) and subjected to freezing (using dry ice and ethanol for $5 \mathrm{~min}$ ) and thawing (at $37^{\circ} \mathrm{C}$ in a water bath for $2 \mathrm{~min}$ ) six times. After the last treatment, the solution was mixed with $200 \mathrm{ml}$ of $0.2 \%$ Triton-X 100 and then heated in $98^{\circ} \mathrm{C}$ water bath for $10 \mathrm{~min}$. The mixture was then incubated with $200 \mu \mathrm{g} / \mathrm{ml}$ of proteinase $\mathrm{K}$ in lysis buffer (100 mM Tris, $\mathrm{pH} 8.0$, $1 \%$ sodium dodecyl sulfate, $25 \mathrm{mM}$ EDTA) at $80^{\circ} \mathrm{C}$ for $2 \mathrm{hr}$, and the DNA was extracted using the routine phenol-chloroform extraction procedure. ${ }^{29}$ The PCR was then carried out using primers specific for E. histolytica and E. dispar (p11 plus 
TABLE 1

Prevalence of single and mixed infections of intestinal protozoans and helminths in the study population based on microscopy*

\begin{tabular}{|c|c|c|c|c|c|c|}
\hline \multirow[b]{2}{*}{ Species } & \multirow{2}{*}{$\begin{array}{l}\text { Total number of } \\
\text { positive cases }\end{array}$} & \multirow{2}{*}{$\begin{array}{l}\text { Prevalence } \\
\text { rate }(\%)\end{array}$} & \multirow{2}{*}{$\begin{array}{l}\text { E. histolytical } \\
\text { E. dispar }\end{array}$} & \multicolumn{2}{|c|}{ Mixed infections with } & \multirow[b]{2}{*}{ Blastocystis sp. } \\
\hline & & & & E. coli & E. nana & \\
\hline \multicolumn{7}{|l|}{ Protozoa } \\
\hline Entamoeba histolytica/E. dispar & 152 & 8.119 & - & $21(3)$ & $3(3)$ & $8(1)$ \\
\hline Entamoeba coli & 126 & 6.730 & $21(3)$ & - & $3(3)$ & $13(1)$ \\
\hline Endolimax nana & 8 & 0.427 & $3(3)$ & $3(3)$ & - & $2(1)$ \\
\hline Blastocystis sp. & 83 & 4.433 & $8(1)$ & $13(1)$ & $2(1)$ & - \\
\hline Giardia intestinalis & 5 & 0.267 & 0 & $1(0)$ & 0 & $1(0)$ \\
\hline \multicolumn{7}{|l|}{ Helminths } \\
\hline Ascaris lumbricoides & 57 & 3.044 & 0 & $8(2)$ & 0 & $15(2)$ \\
\hline Trichuris trichiura & 24 & 1.282 & 0 & $6(4)$ & 0 & $11(4)$ \\
\hline
\end{tabular}

* Numbers in parentheses represent the total number of mixed infections between species.

p12 and p13 plus p14, respectively) as previously described. ${ }^{12}$

Serology. Eleven serum samples of individuals infected with E. histolytica and E. dispar and three samples from healthy controls were collected. The commercially available Amoebiasis HA-Test (Japan Lyophilization Laboratory, Tokyo, Japan) and an indirect hemagglutination assay (IHA) were used to detect antibodies in the serum samples.

Statistical analysis. Prevalence levels were estimated according to each of the variables studied. For measuring the strength of association, we used the Mantel-Haenszel odds ratio (OR) with a $95 \%$ confidence interval (CI). ${ }^{30}$

\section{RESULTS}

Microscopic examinations. The prevalence of all parasites found in the sample of individuals is shown in Table 1. In the course of this study, 1,872 fecal samples were examined. One hundred fifty-two persons were infected with E. histolytica/E. dispar, resulting in a prevalence of $8.119 \%$. Few cases of Endolimax nana and Giardia intestinalis were found, with prevalence rates of $0.427 \%$ and $0.267 \%$, respectively. Infection with E. histolytica/E.dispar was found to be strongly associated with infection by Entamoeba coli. Helminthic eggs of Ascaris lumbricoides (3.044\%) and Trichuris trichiura $(1.282 \%)$ were also observed and found to be associated only with E. coli and Blastocystis sp. but not with E. histolytica/E. dispar (Table 1).

Polymerase chain reaction. Eighteen of the 152 E. histolytica/E. dispar microscopically positive samples were identified as E. histolytica using PCR-specific primers. The remaining 134 samples were found to be $E$. dispar based on the PCR. However, the PCR detected three samples from $E$. coli-positive samples as $E$. dispar. Although we found $21 E$. coli-positive samples in close association with $E$. histolytical $E$. dispar based on microscopy, we failed to identify these three samples coinfected with $E$. dispar. Moreover, no mixed infections of E. histolytica and E. dispar was detected.

Age, sex and geographic distribution of $E$. histolytica and $\boldsymbol{E}$. dispar infections in the study area. The age-specific prevalence is presented in Table 2. Both E. histolytica and E. dispar were most common for those 5-14 years of age, with prevalence rates of $1.509 \%(\mathrm{OR}=2.396,95 \% \mathrm{CI}=$ $0.658-8.730)$ and $9.056 \%(\mathrm{OR}=1.467,95 \% \mathrm{CI}=0.915-$ 2.352 ), respectively. These prevalence rates did not show a statistically significant difference when compared with those of other age groups for either of the two species. However, analysis of the combined prevalence rates of E. histolytica and $E$. dispar in this age group showed that these were statistically significant $(P<0.05)$. On the other hand, subjects less than 1-4 years of age had prevalence rates of $0.635 \%$ for E. histolytica and $6.355 \%$ for E. dispar. In those greater than 45 years of age, the prevalence rates were $0.523 \%$ (OR $=0.823,95 \% \mathrm{CI}=0.085-7.945)$ for $E$. histolytica and $6.806 \%(\mathrm{OR}=1.076,95 \% \mathrm{CI}=0.548-2.111)$ for $E$. dispar.

There was no statistically significant difference between the prevalence rates of E. histolytica in males $(1.086 \%)$ and females $(0.813 \%)$ while in E. dispar, a higher prevalence rate was observed in females $(9.186 \%)$ than in males $(5.731 \%)(\mathrm{OR}=1.664,95 \% \mathrm{CI}=1.174-2.359, P<0.01)$ (Table 3).

The study was carried out in 12 communities of Baguio City and two nearby communities of La Trinidad and Mankayan. The map of the study area is shown in Figure 1 and the prevalence of E. histolytica and E. dispar by geographic

TABLE 2

Age distribution of Entamoeba histolytica- and E. dispar-positive samples as determined by the polymerase chain reaction

\begin{tabular}{|c|c|c|c|c|c|c|c|}
\hline $\begin{array}{l}\text { Age group } \\
\text { (years) }\end{array}$ & Sample size & $\begin{array}{ll} & \text { No. of } \\
\text { E. histolytica }\end{array}$ & $\begin{array}{l}\text { Prevalence } \\
\text { rate }(\%)\end{array}$ & OR $(95 \% \mathrm{CI})^{*}$ & $\begin{array}{l}\text { No. of } \\
\text { E. dispar }\end{array}$ & $\begin{array}{l}\text { Prevalence } \\
\text { rate }(\%)\end{array}$ & OR $(95 \% \mathrm{CI})^{*}$ \\
\hline$<1-4$ & 472 & 3 & 0.635 & $1.00 \dagger$ & 30 & 6.355 & $1.00 \dagger$ \\
\hline $5-14$ & 530 & 8 & 1.509 & $2.396(0.658-8.730)$ & 48 & 9.056 & $1.467(0.915-2.352)$ \\
\hline $15-24$ & 251 & 3 & 1.195 & $1.891(0.389-9.205)$ & 18 & 7.171 & $1.138(0.621-2.086)$ \\
\hline $25-34$ & 258 & 1 & 0.387 & $0.608(0.064-5.754)$ & 17 & 6.589 & $1.039(0.561-1.924)$ \\
\hline $35-44$ & 170 & 2 & 1.176 & $1.861(0.317-10.941)$ & 11 & 6.470 & $1.019(0.499-2.083)$ \\
\hline$>45$ & 191 & 1 & 0.523 & $0.823(0.085-7.945)$ & 13 & 6.806 & $1.076(0.548-2.111)$ \\
\hline Total & 1,872 & 18 & 0.961 & & 137 & 7.318 & \\
\hline
\end{tabular}

* Odds ratio (OR) with $95 \%$ confidence interval (CI)

$\dagger$ Reference point for comparison with other groups. 
TABLE 3

Sex distribution of Entamoeba histolytica- and E. dispar-positive samples as determined by the polymerase chain reaction

\begin{tabular}{lcccccc}
\hline \multicolumn{1}{c}{ Sex } & Sample size & $\begin{array}{c}\text { No. of } \\
\text { E. histolytica }\end{array}$ & $\begin{array}{c}\text { Prevalence } \\
\text { rate }(\%)\end{array}$ & OR (95\% CI)* & $\begin{array}{c}\text { No. of } \\
\text { E. dispar }\end{array}$ & $\begin{array}{c}\text { Prevalence } \\
\text { rate (\%) }\end{array}$ \\
\hline Male & 1,012 & 11 & 1.086 & $1.00 \dagger$ & 58 & 5.731 \\
Female & 860 & 7 & 0.813 & $0.747(0.289-1.929)$ & 79 & 9.186 \\
Total & 1,872 & 18 & 0.961 & & 137 & $1.664(1.174-2.359)$ \\
\hline
\end{tabular}

* Odds ratio (OR) with $95 \%$ confidence interval (CI).

$\dagger$ Reference point for comparison with other groups.

area is listed in Table 4. Entamoeba histolytica was found mostly in the northern part of Baguio City (Ambiong, 3.389\%; Dreamland, Quirino Hill, 1.526\%; Slaughter House, $3.529 \%$ ) and in the communities of La Trinidad (Pico, $1.652 \%$ ) and Mankayan (Sapid, 2.439\%). Entamoeba dispar, on the other hand, was widespread in the whole city but higher prevalence rates were also observed in the northern communities.

Development of antibodies against $\boldsymbol{E}$. histolytica. Of the 155 individuals positive for $E$. histolytica and $E$. dispar by the PCR, only 11 agreed to provide serum samples. Using the commercially-available Amoebiasis HA-Test, we found three samples reactive to E. histolytica antigen. Stool samples from the same individuals showed E. histolytica positivity in the PCR, while the remaining eight samples were identified as E. dispar. The three serum samples collected from healthy controls did not show any reactivity to $E$. histolytica antigen.

\section{DISCUSSION}

Infection with $E$. histolytica is a severe health problem in many tropical and subtropical areas of the world, especially in developing countries. In The Philippines, studies on the prevalence and distribution of E. histolytica are not welldocumented. A previous epidemiologic study using an IHA showed stool positivity prevalence rates of $2-8 \%$ and seropositivity rates of $1-13 \% .{ }^{4}$ However, surveys that determine the prevalence of infection by stool examination of parasites measure predominantly $E$. dispar, since this species is more common, while serologic surveys reflect the incidence of $E$. histolytica infection because $E$. dispar does not show a positive serologic test result. ${ }^{31}$

In this study, we sought to determine the prevalence of $E$. histolytica and E. dispar with our previously reported technique that uses genomic DNA extracted directly from formalin-fixed specimens for the PCR. To our knowledge, this is the first report on the distribution of E. histolytica and $E$. dispar in The Philippines since the description of the two species was established. This survey showed prevalence rates of $0.961 \%$ and $7.318 \%$ for E. histolytica and E. dispar, respectively, in the study population. It is interesting to note that there is an apparent clustering of stool-positive cases of E. histolytica in the northern part of the study area. Entamoeba dispar, on the other hand, was widespread throughout the study sites except in one community where no cases were found. However, high prevalence rates for E. dispar were also found in the northern region. Several factors may account for the high prevalence rates of protozoan and helminthic parasite. These include urbanization, availability of potable water, and population density. In this study, intrafamilial infection with $E$. histolytica was observed in at least

TABLE 4

Geographic distribution of Entamoeba histolytica- and E. dispar-positive samples as determined by the polymerase chain reaction

\begin{tabular}{|c|c|c|c|c|c|c|c|}
\hline Community & Sample size & $\begin{array}{l}\text { No. of } E \text {. } \\
\text { histolytica }\end{array}$ & $\begin{array}{l}\text { Prevalence } \\
\text { rate }(\%)\end{array}$ & $\mathrm{OR}(95 \% \mathrm{CI})^{*}$ & $\begin{array}{c}\text { No. of } \\
\text { E. dispar }\end{array}$ & $\begin{array}{l}\text { Prevalence } \\
\text { rate }(\%)\end{array}$ & OR $(95 \% \mathrm{CI})^{*}$ \\
\hline \multicolumn{8}{|l|}{ North } \\
\hline Sapid, Mankayan & 123 & 3 & 2.439 & & 14 & 11.382 & \\
\hline Pico, La Trinidad & 121 & 2 & 1.652 & & 17 & 14.049 & \\
\hline Ambiong & 118 & 4 & 3.389 & & 13 & 11.016 & \\
\hline Dreamland, Quirino Hill & 131 & 2 & 1.526 & & 11 & 8.396 & \\
\hline Slaughter House & 170 & 6 & 3.529 & & 10 & 5.882 & \\
\hline Fairview Road & 137 & 0 & 0 & & 15 & 10.948 & \\
\hline Subtotal & 800 & 17 & 2.125 & $1.00 \dagger$ & 80 & 10.000 & $1.00 \dagger$ \\
\hline \multicolumn{8}{|l|}{ Central } \\
\hline City Camp Lagoon & 123 & 0 & 0 & & 10 & 8.130 & \\
\hline Lower/Upper QM & 163 & 0 & 0 & & 12 & 7.361 & \\
\hline Mirador Hill & 110 & 0 & 0 & & 0 & 0 & \\
\hline San Luis & 161 & 0 & 0 & & 6 & 3.726 & \\
\hline Campo Sioco & 140 & 0 & 0 & & 4 & 2.857 & \\
\hline Subtotal & 697 & 0 & 0 & $0.032(0.005-0.194)$ & 32 & 4.591 & $0.433(0.286-0.655)$ \\
\hline \multicolumn{8}{|l|}{ South } \\
\hline Smokey Mountain & 135 & 1 & 0.740 & & 11 & 8.148 & \\
\hline Camp 7 & 128 & 0 & 0 & & 9 & 7.031 & \\
\hline Dontogan & 112 & 0 & 0 & & 5 & 4.464 & \\
\hline Subtotal & 375 & 1 & 0.266 & $0.123(0.023-0.673)$ & 25 & 6.666 & $0.643(0.404-1.022)$ \\
\hline Total & 1,872 & 18 & 0.961 & & 137 & 7.318 & \\
\hline
\end{tabular}

* Odds ratio (OR) with $95 \%$ confidence interval $(\mathrm{CI})$

$\dagger$ Reference point for comparison with other groups. 
three households, indicating the possible involvement of human waste disposal systems, personal hygiene habits, housing conditions, and food preparation habits. Aside from the factors mentioned, the apparent clustering in the northern region may be due to the lack of an adequate water supply due to the elevated topography of the study area. Water pipes are inaccessible to the households; thus, they depend on individuals who collect, deliver, and sell water in containers.

With regard to age, as shown in Table 2, E. histolytica and $E$. dispar prevalence rates were particularly high in 514-year-old age group, with an observable decrease in positivity with age. A possible reason for this is decreased exposure of individuals to the parasite. Seroepidemiologic studies in endemic areas of Nicaragua, ${ }^{8}$ Bangladesh, ${ }^{7}$ and Brazil $^{32}$ showed peak prevalences of E. histolytica in a similar age group. Although the purpose of this study was the detection of parasites, a correlation was observed between the presence of E. histolytica in asymptomatic individuals and a positive antibody response in a limited number of serum samples assayed by IHA (one of three seropositive samples from the 5-14-year-old age group). Since only E. histolytica elicits the production of serum antibodies, ${ }^{33}$ the possibility of prior exposure of the individuals to E. histolytica cannot be excluded. However, confirmation of the presence of parasites by the PCR rules out this problem.

Microscopic examinations revealed the presence of other intestinal protozoans as well as helminthic parasites in the study population. A clear association between E. histolytical E. dispar and E. coli was observed. However, coinfection of three additional samples of $E$. coli with $E$. dispar were detected only after the PCR. This also shows the reliability of the PCR in clearly documenting multiple infections among subjects in epidemiologic studies.

Mixed infections of E. histolytica and E. dispar were not observed in the samples tested. This observation was also shown in other studies involving the distribution of E. histolytica and E. dispar in the field. ${ }^{17,28}$ Although it is not yet clear if a competitive phenomenon between E. histolytica and $E$. dispar is true in vivo, an in vitro study showed that only a minuscule amount of E. histolytica can ultimately outgrow $E$. dispar in culture in a given period of time. ${ }^{34}$ Thus, the development of an adequate animal model would be a prerequisite to prove this phenomenon. ${ }^{35}$

It was also observed in this study that all the E. histolytica-positive individuals were asymptomatic. This is consistent with reports from endemic areas that showed that most E. histolytica infections are asymptomatic. ${ }^{36,37}$ Although three bloody stool samples and a few cases of diarrhea were observed among the subjects, based on the PCR results, we could not attribute these to infections with amebae. Moreover, erythrophagocytosis was not observed in bloody stool samples after microscopic examination. Thus, the presence of blood and mucus among individuals with diarrhea maybe due to other factors. ${ }^{17,26}$

This study shows that a clear potential application of PCR-based detection of E. histolytica and E. dispar directly from stools offers the most promise for epidemiologic studies. An additional benefit is that it can be used to monitor the efficacy of treatment, which is usually the limitation of serologic tests because of the persistence of the antibody response even after successful treatment. Moreover, the use of the PCR in detecting E. dispar among cyst carriers can facilitate longitudinal studies to determine the nature of this nonpathogenic species in the hosts.

In conclusion, our results have demonstrated that $E$. dispar infections are predominant in Baguio City and nearby communities in the northern Philippines. However, further studies that include other variables such as socioeconomic conditions, educational backgrounds, and types of settlements are needed to clearly document the epidemiology of amebiasis in the northern Philippines.

Acknowledgments: We are indebted to Virginia de Joya for collaborative support, and Bernadette Baldo, Bernard Padaco and the staff of the Department of Clinical Pathology, Baguio General Hospital and Medical Center, Baguio City, The Philippines for valuable field assistance and laboratory work. We are also grateful to Sumihisa Honda for the statistical analyses, and Miki Kinoshita for the excellent assistance during the preparation of the manuscript.

Financial support: Windell L. Rivera was a recipient of the Japanese Government Ministry of Education, Science, Sports and Culture (Monbusho) Ph.D scholarship. This study was supported in part by the Cooperative Research Grant 1997-9-A-7 of the Institute of Tropical Medicine, Nagasaki University, Japan.

Authors' addresses: Windell L. Rivera and Hiroji Kanbara, Department of Protozoology, Institute of Tropical Medicine, Nagasaki University, 1-12-4 Sakamoto, Nagasaki 852-8523, Japan. Hiroshi Tachibana, Department of Infectious Diseases, Tokai University School of Medicine, Bohseidai, Isehara, Kanagawa 259-1193, Japan.

Reprint requests: Windell L. Rivera, Department of Protozoology, Institute of Tropical Medicine, Nagasaki University, 1-12-4 Sakamoto, Nagasaki 852-8523, Japan.

\section{REFERENCES}

1. World Health Organization, 1997. Entamoeba taxonomy. Bull World Health Organ 75: 291-292.

2. Diamond LS, Clark CG, 1993. A redescription of Entamoeba histolytica Schaudinn, 1903 (Emended Walker, 1911) separating it from Entamoeba dispar Brumpt, 1925. J Eukaryot Microbiol 40: 340-344.

3. Caballero-Salcedo A, Viveros-Rogel M, Salvatierra B, TapiaConyer R, Sepulveda-Amor J, Gutierrez G, Ortiz-Ortiz L, 1994. Seroepidemiology of amebiasis in Mexico. Am J Trop Med Hyg 50: 412-419.

4. Cross JH, Basaca-Sevilla V, 1980. Seroepidemiology of amebiasis in The Philippines. Phil Soc Microbiol Infect Dis J 9: 21-26.

5. Cross JH, Wheeling C, Banzon T, Basaca-Sevilla V, Sevilla J, 1977. Amoebiasis and intestinal parasitic infections in a population on Cebu Island, The Philippines. Ann Trop Med Parasitol 71: 435-441.

6. Gonzalez CR, Isibasi A, Ortiz-Navarrete V, Paniagua J, Garcia JA, Ramirez A, Salvatierra B, Tapia R, Sepulveda J, Gutierrez G, Kumate J, 1995. Prevalence of antibodies against Entamoeba histolytica in Mexico measured by ELISA. Epidemiol Infect 115: 535-543.

7. Hossain MM, Ljungstrom I, Glass RI, Lundin L, Stoll BJ, Huldt G, 1983. Amebiasis and giardiasis in Bangladesh: parasitological and serological studies. Trans $R$ Soc Trop Med Hyg 77: 552-554.

8. Sierra AT, Ruiz LC, Kettis AA, Huldt G, Jonsson J, Schroeder H, 1992. Amebiasis in Nicaragua: class specific serum antibody responses. Arch Med Res 23: 261-264.

9. Sargeaunt PG, Williams JE, Grene JD, 1978. The differentiation of invasive and non-invasive Entamoeba histolytica by isoenzyme electrophoresis. Trans $R$ Soc Trop Med Hyg 75: 519521.

10. Bracha R, Diamond LS, Ackers JP, Burchard GD, Mirelman D, 
1990. Differentiation of clinical isolates of Entamoeba histolytica by using specific DNA probes. J Clin Microbiol 28: 680-684.

11. Garfinkel LI, Giladi M, Huber M, Gitler C, Mirelman D, Revel M, Rozenblatt S, 1989. DNA probes specific for Entamoeba histolytica possessing pathogenic and nonpathogenic zymodemes. Infect Immun 57: 926-931.

12. Tachibana H, Kobayashi S, Takekoshi M, Ihara S, 1991. Distinguishing pathogenic isolates of Entamoeba histolytica by polymerase chain reaction. $J$ Infect Dis 164: 825-826.

13. Acuna-Soto R, Samuelson J, De Girolami P, Zarate L, MillanVelasco F, Schoolnick G, Wirth D, 1993. Application of the polymerase chain reaction to the epidemiology of pathogenic and nonpathogenic Entamoeba histolytica. Am J Trop Med Hyg 48: 58-70.

14. Clark CG, Diamond LS, 1991. Ribosomal RNA genes of 'pathogenic' and 'nonpathogenic' Entamoeba histolytica are distinct. Mol Biochem Parasitol 49: 297-302.

15. Cruz-Reyes JA, Spice WM, Rehman T, Gisborne E, Ackers JP, 1992. Ribosomal DNA sequences in the differentiation of pathogenic and nonpathogenic isolates of Entamoeba histolytica. Parasitology 104: 239-246.

16. Tachibana H, Ihara S, Kobayashi S, Kaneda Y, Takeuchi T, Watanabe Y, 1991. Differences in genomic DNA sequences between pathogenic and nonpathogenic isolates of Entamoeba histolytica identified by polymerase chain reaction. J Clin Microbiol 29: 2234-2239.

17. Tachibana H, Kobayashi S, Paz KC, Aca IS, Tateno S, Ihara S, 1992. Analysis of pathogenicity by restriction-endonuclease digestion of amplified genomic DNA of Entamoeba histolytica isolated in Pernambuco, Brazil. Parasitol Res 78: 433436.

18. Tannich E, Horstmann RD, Knobloch J, Arnold HH, 1989. Genomic DNA differences between pathogenic and nonpathogenic Entamoeba histolytica. Proc Natl Acad Sci USA 86: $5118-5122$.

19. Tannich E, Burchard GD, 1991. Differentiation of pathogenic from nonpathogenic Entamoeba histolytica by restriction fragment analysis of a single gene amplified in vitro. J Clin Microbiol 29: 250-255.

20. Petri WA Jr, Jackson TFHG, Gathiram V, Kress K, Saffer LD, Snodgrass TL, Chapman MD, Keren Z, Mirelman D, 1990. Pathogenic and nonpathogenic strains of Entamoeba histolytica can be differentiated by monoclonal antibodies to the galactose-specific adherence lectin. Infect Immun 58: 18021806.

21. Tachibana H, Kobayashi S, Cheng XJ, Hiwatashi E, 1997. Differentiation of Entamoeba histolytica from E. dispar facilitated by monoclonal antibodies against a $150-\mathrm{kDa}$ surface antigen. Parasitol Res 83: 435-439.

22. Tachibana H, Kobayashi S, Kaneda Y, Takeuchi T, Fujiwara T, 1997. Preparation of a monoclonal antibody specific for En- tamoeba dispar and its ability to distinguish E. dispar from E. histolytica. Clin Diag Lab Immunol 4: 409-414.

23. Tachibana H, Kobayashi S, Kato Y, Nagakura K, Kaneda Y, Takeuchi T, 1990. Identification of a pathogenic isolate-specific 30,000-Mr antigen of Entamoeba histolytica by using a monoclonal antibody. Infect Immun 58: 955-960.

24. Tachibana H, Kobayashi S, Nagakura K, Kaneda Y, Takeuchi T, 1991. Reactivity of monoclonal antibodies to species-specific antigens of Entamoeba histolytica. J Protozool 38: 329-334.

25. Haque R, Kress K, Wood S, Jackson TFHG, Lyerly D, Wilkins T, Petri WA Jr, 1993. Diagnosis of pathogenic Entamoeba histolytica infection using a stool ELISA based on monoclonal antibodies to the galactose-specific adhesin. J Infect Dis 167: 247-249.

26. Haque R, Faruque ASG, Hahn P, Lyerly DM, Petri WA Jr, 1997. Entamoeba histolytica and Entamoeba dispar infection in children in Bangladesh. J Infect Dis 175: 734-736.

27. Mirelman D, Nuchamowitz Y, Stolarsky T, 1997. Comparison of use of enzyme-linked immunosorbent assay-based kits and PCR amplification of rRNA genes for the simultaneous detection of Entamoeba histolytica and E. dispar. J Clin Microbiol 35: 2405-2407.

28. Rivera WL, Tachibana H, Silva-Tahat MRA, Uemura H, Kanbara H, 1996. Differentiation of Entamoeba histolytica and E. dispar DNA from cysts present in stool specimens by polymerase chain reaction: its field application in The Philippines. Parasitol Res 82: 585-589.

29. Sambrook J, Fritsch EF, Maniatis T, 1989. Molecular Cloning: A Laboratory Manual. Cold Spring Harbor, NY: Cold Spring Harbor Laboratory Press.

30. Kahn HA, Sempos CT, 1989. Statistical Methods in Epidemiology. New York: Oxford University Press, 45-71, 85-136.

31. Petri WA Jr, 1996. Recent advances in amebiasis. Crit Rev Clin Lab Sci 33: 1-37.

32. Braga LL, Lima AAM, Sears CL, Newman RD, Wuhib T, Paiva CA, Guerrant RL, Mann BJ, 1996. Seroepidemiology of Entamoeba histolytica in a slum in northeastern Brazil. Am J Trop Med Hyg 55: 693-697.

33. Jackson TFHG, Ravdin JI, 1996. Differentiation of Entamoeba histolytica and Entamoeba dispar infections. Parasitol Today 12: 406-409.

34. Clark CG, Diamond LS, 1993. Entamoeba histolytica: an explanation for the reported conversion of "nonpathogenic" amebae to the "pathogenic" form. Exp Parasitol 77: 456460.

35. Clark CG, 1995. Evolution of virulence in Entamoeba histolytica. Trop Dis Bull 92: R147-R155.

36. Jackson TFHG, Gathiram V, Simjee AE, 1985. Seroepidemiologic study of antibody responses to the zymodemes of Entamoeba histolytica. Lancet 1: 716-721.

37. Ravdin JI, Jackson TFHG, Petri WA Jr, Murphy CF, Ungar BLP, Gathiram V, Skilogiannis J, Simjee AE, 1990. Association of serum antibodies to adherence lectin with invasive amebiasis and asymptomatic infection with pathogenic Entamoeba histolytica. J Infect Dis 162: 768-772. 